\title{
Unnecessary hysterectomies and our role as interventional radiology community
}

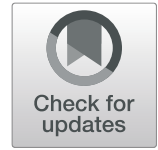

Gregory C. Makris ${ }^{1,2^{*}}$, Saqib Butt ${ }^{1}$ and Tarun Sabharwal ${ }^{1}$

Keywords: Hysterectomy, Uterine artery embolization

To the Editor,

We read with interest the article by de Bruijn and colleagues(de Bruijn et al. 2019) who reported that despite the inclusion of uterine artery embolization (UAE) in the management of heavy menstrual bleeding in Dutch national guidelines, the UAE to hysterectomy ratio remained low at $6.9 \%$, with no increase following the introduction of these new guidelines.

Such low UAE rates are not isolated to the Netherlands. Spanish data suggests approximately 145 UAEs performed annually in a population of over 44 million,(https://interventionalnews.com/uae-surgery-disparity-worldwide/?hilite=\%27fibroid\% $27 \% 2 \mathrm{C} \% 27 \mathrm{emboli}$ zation\%27 n.d.) whilst in France an average of 2000 UAEs are performed per annum compared to 40,000 hysterectomies.(https://interventionalnews.com/uae-surgery-disparity-worldwide/?hilite=\%27fibroid $\% 27 \% 2$ C\%27embolization\%27 n.d.) Data from the national heavy menstrual bleeding audit in the UK revealed that of the 6195 women who were treated surgically, only 129 (2\%) had UAE.(Geary et al. 2019) A similar picture persists outside of Europe. Australian Medicare data reveals an average of less than 200 UAEs performed per year,(Al-Fozan et al. 2002) whilst in the USA, 65 times more hysterectomies are performed than UAEs.(Narayanyan et al. 2017) This is concerning, especially in light of trial evidence showing that two thirds of women treated with UAE remain hysterectomy free at 10 years.(de Bruijn et al. 2016) In addition, there is no difference in patient satisfaction between UAE and

\footnotetext{
* Correspondence: g.makris09@doctors.org.uk

'Vascular and Interventional Radiology Department, Guy's and St Thomas' Hospital, NHS Foundation Trust, Westminster Bridge Road, London SE1 7EH, UK

${ }^{2}$ Alfa Institute of Biomedical Sciences, Neapoleos 9, Marousi, Athens, Greece
}

hysterectomy at 5 years, whilst the duration of procedure, length of hospital stay and time taken to resume normal activities may be shorter in UAE relative to hysterectomy or myomectomy.(Gupta et al. 2014) Further supporting treatment with UAE, twenty year follow up cohort studies demonstrate an increased risk of metabolic and cardiovascular conditions following hysterectomy, especially in women under 35.(LaughlinTommaso et al. 2018)

Patient awareness of UAE remains concerningly low. A report by the Society of Interventional Radiology in 2017 found that $62 \%$ of women had never heard of the treatment.(The fibroid fix 2017) Of the women who were aware of UAE, almost three quarters did not first hear of it from their gynaecologist, suggesting that despite the wealth of high quality evidence, gynaecologists are failing to offer this safe, effective, minimally invasive treatment to their patients.

We believe that at a local level this could be remedied by involvement of interventional radiologists at gynaecology multidisciplinary team (MDT) meetings and the patient counselling process. The regional situation in the UK is complicated by funding for procedures being devolved to clinical commissioning groups, allowing a postcode lottery to exist whereby UAE is funded in some regions but not others. With increased awareness amongst patient groups and general practitioners in addition to the large body of evidence demonstrating clinical and cost effectiveness, the case for funding UAE is a strong one. Nationally, closer collaboration between interventional radiology and gynaecology societies would also help to increase awareness amongst referring gynaecologists. 
In short, the interventional radiology community must continue to address the injustice of chronic underutilisation of this minimally invasive, safe, clinically and cost effective procedure. Engaging with relevant stakeholders and lobbying at social and political levels is crucial for the success of this endeavour.

\section{Acknowledgements}

Not applicable.

\section{Authors' contributions}

All authors read and approved the final manuscript.

\section{Authors' information}

NA

\section{Funding}

No funding received.

\section{Availability of data and materials}

Not applicable.

Ethics approval and consent to participate

Not applicable.

\section{Consent for publication}

Not applicable.

\section{Competing interests}

The authors declare that they have no competing interests.

Received: 1 July 2020 Accepted: 10 July 2020

Published online: 14 July 2020

\section{References}

Al-Fozan H, Dufort J, Kaplow M, Valenti D, Tulandi T (2002) Cost analysis of myomectomy, hysterectomy, and uterine artery embolization. Am J Obstet Gynecol 187:1401-1404. https://doi.org/10.1067/mob.2002.127374

de Bruijn AM, Ankum WM, Reekers JA et al (2016) Uterine artery embolization vs hysterectomy in the treatment of symptomatic uterine fibroids: 10-year outcomes from the randomized EMMY trial. Am J Obstet Gynecol 215(6):745. e1-745.e12. https://doi.org/10.1016/.ajog.2016.06.051

de Bruijn AM, Huisman J, Hehenkamp WJK et al (2019) Implementation of uterine artery embolization for symptomatic fibroids in the Netherlands: an inventory and preference study. CVIR Endovasc 2:18. https://doi.org/10.1186/s42155019-0061-5

Geary RS, Gurol-Urganci I, Kiran A et al (2019) Factors associated with receiving surgical treatment for menorrhagia in England and Wales: findings from a cohort study of the National Heavy Menstrual Bleeding Audit. BMJ Open 9: e024260

Gupta JK, Sinha A, Lumsden MA, Hickey M. Uterine artery embolization for symptomatic uterine fibroids. Cochrane Database Syst Rev 2014, Issue 12. Art. No.: CD005073. doi: https://doi.org/10.1002/14651858.CD005073.pub4

https://interventionalnews.com/uae-surgery-disparity-worldwide/?hilite= \%27fibroid\%27\%2C\%27embolization\%27 Accessed 8/6/20 n.d.

Laughlin-Tommaso SK, Khan Z, Weaver AL, Smith CY, Rocca WA, Stewart EA

(2018) Cardiovascular and metabolic morbidity after hysterectomy with ovarian conservation: a cohort study. Menopause. 25(5):483-492. https://doi. org/10.1097/GME.0000000000001043

Narayanyan S (2017) Nationwide Analysis of Hospital Characteristics, Demographics, and Cost of Uterine Fibroid Embolization. Society of Interventional Radiology Annual Scientific Meeting;Abstract 106.

Poll H. The fibroid fix: What women need to know. Society of interventional radiology; Executive report.

\section{Publisher's Note}

Springer Nature remains neutral with regard to jurisdictional claims in published maps and institutional affiliations.

\section{Submit your manuscript to a SpringerOpen ${ }^{\circ}$ journal and benefit from:}

- Convenient online submission

- Rigorous peer review

- Open access: articles freely available online

- High visibility within the field

- Retaining the copyright to your article

Submit your next manuscript at $\boldsymbol{\nabla}$ springeropen.com 